\title{
Language Interpreting in Undergraduate Medical Education: Developing a Framework for Educational Practice
}

\author{
Dr. Ann Donohoe (Corresponding author) \\ School of Nursing and Midwifery \\ Royal College of Surgeons in Ireland (RCSI) Bahrain, \\ Adliya, Kingdom of Bahrain \\ E-mail: adonohoe@rcsi-mub.com Tel: +973-16-660-191 \\ Dr. Wendy Maddison \\ Student Development and Wellbeing Department \\ Royal College of Surgeons in Ireland (RCSI) Bahrain
}

Dr. Jean Hughes

Student, Academic and Regulatory Affairs

Royal College of Surgeons in Ireland (RCSI) Bahrain

Ms. Alaa Basha

School of Medicine

Royal College of Surgeons in Ireland (RCSI) Bahrain

Ms. Lana Dardari

School of Medicine

Royal College of Surgeons in Ireland (RCSI) Bahrain 
Dr. Abraham Kayal

School of Medicine

Royal College of Surgeons in Ireland (RCSI) Bahrain

Received: September 9, 2021 Accepted: September 30, 2021 Published: October 5, 2021

doi:10.5296/ijld.v11i3.19076

URL: https://doi.org/10.5296/ijld.v11i3.19076

\begin{abstract}
Linguistic differences between patients and clinicians can result in ineffective and inequitable healthcare delivery. Medical students should therefore be facilitated to develop the requisite knowledge and skills to work effectively within language discordant clinical situations. This paper explores language interpreting processes in an undergraduate medical education programme. The study utilizes a constructivist paradigm incorporating an action research approach. Action Research Cycle 1 (ARC1) examines the use of interpreters during clinical examinations while Action Research Cycle 2 (ARC2) focuses on language translation technology. In Action Research Cycle 3 the data that was generated in ARC 1 and ARC 2 is reviewed in association with international literature to develop a framework for practice. This study demonstrates that language interpreting procedures should be based within a collaborative framework with students, interpreters and educators receiving appropriate educational preparation, predicated on a cross cultural approach to care.
\end{abstract}

Keywords: International student experience, international undergraduate medical education, language interpreting in healthcare, qualitative research, action research, Middle East

\title{
1. Introduction
}

Evidence from published research illustrates the negative impact of language barriers on healthcare access, patient satisfaction and experience, as well as disparities in receipt of care between the dominant language proficient patients and those facing language barriers (Bowen, 2015). Patients with limited proficiency in the physicians' language are more likely to receive less health education, poorer interpersonal care, and report lower patient satisfaction when compared to patients with language-concordant providers (Ngo-Metzger et al., 2007). Language barriers also appear to increase the risks to patient safety (Divi, Koss, Schmaltz, \& Loeb, 2007; van Rosse, de Bruijne, Suurmond, Essink-Bot, \& Wagner, 2016). Linguistic specific solutions to this problem include the provision of trained and untrained interpreters, telephone interpretation, multilingual staff members and mobile technology (Chan et al., 2010). While each method carries a specific set of advantages and disadvantages, patients with language-discordant providers often experience limited access to appropriate interpreting services (Ngo-Metzger et al., 2007).

The various complexities associated with language interpreting processes further compound 
the problem. While interpreters are trained to interpret the spoken word and translators work with written words, the two professions are often confused, with the terms being used interchangeably and at times incorrectly (Juckett \& Unger, 2014). In practice, the interpreting process involves converting a message from one language to another through the completion of a series of intricate tasks in the space of a few seconds (Cambridge, Singh, \& Johnson, 2012). These interpreter-mediated interactions are significantly influenced by a complex interplay of social, cultural, and interactional factors, shaping and constraining the communicative actions of the various participants (Pasquandrea, 2011). A systematic review by Flores (2005) on the impact of medical interpreter services on the quality of health care, demonstrated that optimal communication, patient satisfaction, improved outcomes and fewer interpreter errors occur when patients have access to trained professional interpreters. A later review by Karliner, Jacobs, Chen, and Mutha (2007) similarly concluded that working with professional interpreters raises the quality of clinical care. However, Brisset, Leanza, and Laforest (2013) in their systematic review, noted that untrained interpreters are appreciated by patients and can be seen as allies in the healthcare process. Furthermore, the constraints of modern healthcare are such that institutions and practitioners are required to utilize the services of untrained interpreters, therefore the pros of informal interpreting should be better acknowledged (Brisset et al., 2013). What is clear is that working with an interpreter requires adjustment from a dyadic to a triadic interaction and is a complex skill that should be included in all medical communication training (Rosenberg, Leanza, \& Seller, 2007). Undergraduate medical education provides a critical target for intervention in this regard (Friedman-Rhodes \& Hale, 2010; McEvoy, Santos, Marzan, Green, \& Milan, 2009; Rodriguez, Cohen, Betancourt, \& Green, 2011), as focused education at undergraduate level leads to earlier proficiency in using interpreters (Omoruyi, Dunkle, Dendy, McHugh, \& Barratt, 2018). Furthermore, equipping students with these skills as part of their medical school training can help to facilitate a culture of proper interpreter use (McEvoy et al., 2009).

It is against this rather mercurial background that the current investigation was developed. The study was set within the context of an undergraduate medical education programme delivered at a European university in the Middle East. As part of the assessment process, final year medical students undertake two 'long case' examinations where students must take a history, perform a relevant physical examination, formulate a diagnosis and recommend a patient treatment plan. The patients are drawn from the current in-patient or outpatient cohort and generally speak little or no English. As all examinations are conducted through English, the official language of the university, bilingual hospital/ university staff facilitate communication during these examinations by acting as interpreters. While the process is evaluated positively, further educational guidance is required. Consequently, this study was designed to explore the language interpreting processes in the undergraduate medical education programme, with a view towards developing a framework to inform practice.

\section{Methods}

\subsection{Action Research}

The study was guided by a constructivist paradigm incorporating an action research (AR) 
approach. The constructivist paradigm as advanced by Guba and Lincoln (1989) conceptualizes inquiry as a process that begins with the issues and concerns of participants and which unfolds through a dialectic of iteration, analysis, critique, reiteration and reanalysis that leads eventually to a joint construction of a case (Schwandt, 1994). AR fundamentally reflects constructivist thinking as both approaches operate on the basic principle of a search for meaning (Trunk Sirca \& Shapiro, 2007). However, AR is also aimed at taking action and creating knowledge and/or theory about that action as the action unfolds (Coghlan, 2019). As such it extends constructivist inquiry beyond a search for meaning or co-construction of knowledge, into the realm of taking action to both understand and improve the social reality of participants.

\subsection{Study Design}

The design of this study was based on the Action Research Spiral as devised by Kemmis and McTaggart (1988). Action Research Cycle 1 (ARC1) focused on exploring the benefits and challenges associated with the traditional approach of using an interpreter during clinical examinations. In Action Research Cycle 2 (ARC2) students were provided with a language translating earpiece which connected to a cloud-based translation system which facilitated real-time language conversion from Arabic to English and vice versa. ARC 2 therefore focused on evaluating the use of this mobile translation device within the context of a mock clinical examination. In Action Research Cycle 3 (ARC 3) the data that was generated in ARC 1 and ARC 2 was analyzed in association with international literature to develop a framework to guide practice. Institutional ethical approval was granted for the study by the University Human Research Ethics Committee.

\subsection{Sampling}

The process used to recruit participants was strongly influenced by Guba and Lincoln's (1989) view of constructivism, where truth is viewed as a matter of the best informed and most sophisticated construction on which there is consensus at a given time (Schwandt, 1994). A purposive sampling strategy was used as this approach involves the selection of individuals or groups of individuals that are proficient and well-informed about the phenomenon being examined (Creswell \& Creswell, 2017). Consequently, it was important that all stakeholders with a direct knowledge of the process (i.e., students, interpreters, professors and external examiners) were offered the opportunity to take part in the study. An invitation to participate including a participant information leaflet and consent form was issued to all final year medical students who had undertaken a long case exam using an interpreter. A similar invitation was emailed to all interpreters, professors and external examiners who were directly involved in the examination process. Using purposive sampling in this way reflected a constructivist methodology by facilitating the co-construction of knowledge through dialogue and interaction with well-informed others.

\subsection{Data Collection}

Two different types of qualitative interview were used to collect the data: focus groups and semi-structured interviews. The integration of focus group and individual interview data is 
viewed as a productive strategy that can lead to an enhanced description of a phenomenon while also augmenting data richness (Lambert \& Loiselle, 2008). Focus group interviews are designed to tap into the dynamics of a group conversation while explicitly using group interaction as part of the method (Kitzinger, 1995). Individual interviews are considered to produce more detail than focus groups, and offer more insight into a respondent's personal thoughts, feelings, and world view (Morgan, Krueger, \& Scannell, 1998). As the students and the interpreters formed what Kitzinger (1995) termed naturally occurring groups, focus group interviews were used to collect data from these two cohorts. As the professors and examiners occupied a more autonomous role, individual semi-structured interviews were deemed to be a more appropriate data collection method for these participants. An interview guide was used to standardize the focus group and individual interview process in both ARC1 and ARC2. The guide was designed to invite participants to identify the benefits, challenges and opportunities associated with the language interpreting process that they had experienced; human interpreter (ARC 1) or translation device (ARC2). In ARC1 six semi-structured interviews were conducted; five were with individual professors while one was conducted with an external examiner. Three focus groups were also conducted: two with interpreters and one with students. In ARC2, individual semi-structured interviews were conducted with two examiners, while one focus group was conducted with students. The focus groups were limited to between 4-6 participants as smaller focus groups are deemed to be more comfortable for participants (Krueger \& Casey, 2015) and in this context also facilitated greater group interaction.

\subsection{Data Analysis}

Thematic analysis is described by Clarke and Braun (2017) as a process which identifies, analyses and describes patterns of meaning within data. It is primarily designed for use within a qualitative paradigm (Braun \& Clarke, 2006) and it was particularly suited to this study due to its organic approach to coding and theme development. The thematic analysis process consists of six phases; familiarization with the data; generating initial codes; searching for themes; reviewing themes; defining and naming themes and producing the report (Braun \& Clarke, 2006). In the initial phase of familiarization with the data, the transcripts were read repeatedly to gain an in-depth knowledge of the content. In phase two, manual coding was used to generate initial codes which were later confirmed through further analysis using the qualitative software package Dedoose. Codes with a similar content were combined into preliminary themes which were then reviewed against the coded data and the dataset to ensure they reflected the transcripts (searching for themes). These themes were then revised and combined (reviewing themes) resulting in the generation of four overarching themes. Further refinements were made so that the theme name, definition, content and direct quotation(s) were consistent (defining and naming the themes). The process culminated in the development of a provisional report of the findings. To enhance the trustworthiness of the data, member validation was undertaken by inviting participants to review the report, where they were encouraged to verify and comment on the preliminary findings. 


\section{Findings}

The thematic analysis process generated the following four themes: Added value; Knowledge and Communication; Learning Together and Technological Solutions.

\subsection{Theme 1-Added-Value}

The participants described how working through an interpreter added value that extended beyond the language interpreting process. Students recognized how working with an interpreter was a key part of their undergraduate medical education, while the professors viewed the experience as valuable preparation for the student's future role as a doctor. One professor commented:

"...it's a good skill to have as an international medical graduate, that they have used translators (sic) and know the pluses and minuses of this".

Other professors acknowledged how using interpreters enabled them to include a wide variety of patients which resulted in students gaining exposure to a more diverse range of clinical cases and medical conditions. Furthermore, students gained access to patients with conditions that were particularly prevalent in the Middle Eastern region. The interpreters also identified the benefits of their role. They described how they took great pride in their position and were keenly attuned to caring for the patient during the examination process. The interpreters stated that they felt confident in their abilities to manage the language interpreting process and overall perceived the role as being valued and respected.

As one interpreter stated;

"It is good, we get a lot of positive things...., we get a lot of information from the students, from the professors, from the patients also. Which is good, I feel it is all positive."

\subsection{Theme 2 - Knowledge and Communication}

While the role of the interpreter was to communicate conversations verbatim, students, professors and examiners noted that at times interpreters appeared to modify what was being said. The interpreters explained that sometimes it was not possible to provide a literal translation due to linguistic and cultural issues. An interpreter captured the linguistic complexities as follows;

"......sometimes the student will say a medical term that I understand as a translator (sic) but I cannot translate into Arabic, as sometimes there is no actual translation of it in Arabic".

Overall, the students found the process of working through an interpreter quite challenging. Many of the professors observed that despite specific in-house preparation, students sometimes inadvertently spoke in the third person as opposed to the first person. Students reported that they found it difficult to communicate with the patient or to establish a rapport when using an interpreter. One student stated;

"The problem is that we want to use our communication skills with the patient.... If we want to express concern for them or apologize, we might say it in a specific tone but that won't get 
translated".

\subsection{Theme 3 - Learning Together}

There was widespread agreement that the various stakeholders should learn together. An examiner suggested the establishment of an oversight committee where representatives from students, patients, interpreters and educators could discuss various issues associated with the interpreting process. There was also general agreement that specific standards and guidelines were required with the interpreters being particularly keen to receive additional practical guidance. As one interpreter explained:

"It is to have standardized guidelines.....to be guided where you sit, where you talk, when to stop, how you are translating, and how fast you can be...".

There was an emphasis on learning together through practical workshops. Students suggested joint workshops with interpreters so that they could practice together. Similarly, interpreters suggested practical workshops with students, but also proposed the inclusion of patients. The professors concurred with this approach and stressed the importance of scheduling sessions early in the programme so that participants would have adequate time to develop the necessary skills.

\subsection{Theme 4 - Technological Solutions}

The participants reported that the mobile device had limited applicability. This was due primarily to connectivity issues associated with using several devices in proximity. One student commented that:

"I felt like there was no flow, because the device kept disconnecting and reconnecting, so it was very hard to maintain a flow of conversation with the patient".

Both students and examiners noted that translation from Arabic to English was particularly problematic due to the range of Arabic dialects in use. Some students found that the mobile device did not work properly when they were wearing the hijab (Islamic scarf). Other students reported that the device was uncomfortable to wear and found sharing devices unhygienic. On a positive note, the participants could see the potential advantages of using mobile technology and recognized the value of conducting future research in this area. However, there was widespread agreement that an interpreter was significantly preferable to using a mobile device/app. As one student stated;

"I believe that there are more improvements to be made to the device, it is still at an early stage, I think it is a very good idea, but for now, I think it is better to stay with the human translator".

\section{Discussion}

\subsection{Discussion}

The findings from this study illustrate many of the challenges associated with language interpreting processes. It is interesting to note that all participants uniformly used the term 
translator as opposed to the more accurate term interpreter, which reflects the complexities of the nomenclature as described by Juckett and Unger (2014). Another prominent feature relates to the conflicting expectations that surround the interpreter's role. Students, professors and examiners expected literal word for word conversions, whereas the interpreters explained that at times this was impractical due to linguistic, contextual and/or cultural complexities. Similar findings are reflected in the interpreting studies literature, where the role of the interpreter is often conceptualized as being on a continuum from neutral invisible conduit to active cultural linguist (Beltran Avery, 2001; Cox, 2015). In the conduit model the interpreter is passive within the clinical encounter and is viewed as a 'black box' (Beltran Avery, 2001) (p 4) in which messages are entered in one language and reproduced in another. On the other end of the continuum the interpreter is visibly active in the encounter and draws on both their cultural and linguistic knowledge to understand intended meanings while making the appropriate equivalent conversions (Beltran Avery, 2001). This study illustrates that students, professors and examiners expected the interpreter to act as an invisible conduit, i.e., to provide literal word conversions without additional involvement. However, the interpreters reported that they were required to adopt a more active role which encompassed cultural as well as linguistic functions. This study illustrates that students, professors and examiners expected the interpreter to act as an invisible conduit This is an interesting finding as it demonstrates how a dissonance in perception and expectation can adversely impact the language interpreting process.

The students in this study viewed the interpreted encounter as a challenging experience. Lie, Bereknyei, and Vega (2010), who explored longitudinal skill development in medical students noted that the skills required to work effectively with interpreters do not necessarily track with general communication skills. Furthermore, without a formal curriculum these skills do not naturally improve over time and have the potential to deteriorate in the absence of active reinforcement (Lie et al., 2010). A variety of recent studies demonstrate how certain curricular interventions can be used to facilitate medical students to work with interpreters. These strategies range from bespoke workshops (Coetzee, Pereira, Scheurer, \& Olson, 2020) and educational sessions (McEvoy et al., 2009) to formal interpreter training courses (Diaz et al., 2016) and e-learning modules (Ikram, Essink-Bot, \& Suurmond, 2015). However, preparing students to work with interpreters is only part of the educational equation and such interventions must be firmly situated within a cross-cultural curriculum. As Betancourt (2003) states, the goal of such curricula is to prepare students to care for patients from diverse backgrounds, and to recognize and address social, racial, cultural, and gender biases in health care delivery.

This study also provided a relatively unique insight into the perspective of interpreters. While numerous studies have explored challenges in the doctor-interpreter-patient medical encounter, the perspective of the interpreter is often side-lined (Seidelman \& Bachner, 2010). The findings demonstrate that despite specific training, the interpreters struggled to balance the competing demands of the various parties and consequently experienced role conflict. Brisset et al. (2013), describe how interpreters can change their position along the continuum from conduit to commitment (loyalty to the patient). The more committed they are to the 
patient the less neutral they are perceived to be, resulting in practitioners sensing a loss of control over the consultation (Brisset et al., 2013). This finding points to the need for additional training and education of interpreters. However, like student preparation, the focus should extend beyond the interpreting process and be firmly situated within a cross-cultural approach to care.

Another significant feature of this study relates to the participants' willingness to learn together. Krystallidou et al. (2018) suggests that the lack of synergy between doctors and interpreters may be due to medical student education which relies on full language concordance (i.e., the clinician and patient are proficient in each other's language) and medical interpreter training which pays limited attention to the intricacies of clinical communication (Krystallidou, 2014). While the joint training of healthcare providers and interpreters is viewed as a possible way forward (Cambridge et al., 2012) the need to include exposure to real-life professional practice is also required (González-Davies \& Enríquez-Raído, 2016). The aim is to develop what Krystallidou et al. (2018) refer to as 'doctor-minded interpreters and interpreter-minded doctors' who work together towards attaining the provision of high-quality, patient-centred care for the linguistically disadvantaged patient population. However, there was also a recognition that such initiatives require robust governance structures at both a programme and at an institutional level.

Another relatively unique feature of this study is that it explored the use of language translation technology. Few studies have evaluated the use of translation apps in health care settings and even fewer have examined the contexts in which their use may be suitable (Albrecht, Behrends, Matthies, \& von Jan, 2013). In this study the mobile device was poorly evaluated due, primarily, to issues associated with accuracy and connectivity. Consequently, there was widespread agreement that an interpreter was significantly preferable to using a technological device/app. However, participants also recognized the potential of translation technology and called for further research in this area. These findings support the view that an interpreter remains the gold standard for medical discussions and interactions (Albrecht et al., 2013; Chang, Thyer, Hayne, \& Katz, 2014). Although there is limited evidence for the effective use of translation technology in medical/health care settings (Panayiotou et al., 2019) translation applications may potentially have a role in reducing language barriers in everyday healthcare communication (Panayiotou et al., 2020). Consequently, there is a need to explore the feasibility of utilizing various language interpretation software applications within healthcare settings. However, this line of inquiry should form part of a comprehensive research strategy that is designed to explore both interpreter and technology-based interpreting processes, ranging from users' experiences and standards of practice, through to accuracy and ease of use.

While some very interesting findings were identified, the study had context specific limitations. The research was conducted in one medical school, situated within a Middle Eastern learning environment and cultural context. Patients could not be included due to pre-existing challenges associated with recruiting participants for the long case clinical examinations. In addition, trained interpreters were unavailable and therefore not included in the sample. However, the decision to view the findings through the lens of international 


\section{Macrothink}

literature has ensured that the outcomes are relevant to healthcare contexts internationally. Furthermore, the study represents an important reference point for future research into language interpreting process in healthcare and higher education.

\subsection{Developing a Framework for Practice.}

The findings were used in association with the literature to devise the framework 'Language Interpreting Processes: A Guide for Educational Practice'. The framework, which is presented in Figure 1. is comprised of four cornerstones; Student Education; Interpreter Education; Governance Procedures and Research Strategy.

Student education should include techniques in working with both trained and untrained interpreters, focusing on the differences in communication dynamics as well as the advantages/limitations of the various types of interpreting processes (Brisset et al., 2013). With regards to interpreter education, developing in-house interpreters is seen as a viable solution (Larrison, Velez-Ortiz, Hernandez, Piedra, \& Goldberg, 2010) and offers institutions the opportunity to provide bespoke interpreter training programs. However, the effective preparation of students and interpreters is only part of the solution and it is important that such educational interventions are situated within a cross cultural curriculum aimed at strengthening the learner's ability to care for patients from diverse backgrounds (Betancourt, 2003). The third cornerstone points to the need for clear governance procedures that reflect the specific educational, linguistic and cultural contexts in which the language interpreting process is situated. Such procedures should also address the recruitment of a greater number of bilingual providers to meet the health care needs of our increasingly diverse populations (Ngo-Metzger et al., 2007). The fourth cornerstone involves conducting research into language interpreting processes/practices and should include further exploration of language interpretation software. The final element of the framework relates to collaboration and partnership and emphasizes the need for relevant stakeholders (i.e. students, patients, interpreters and educators) to work together to develop effective language interpreting services at a programme and at an institutional level. While the framework was initially devised for medical and health professions education it also has applicability within the broader domain of language interpreting/linguistics education. 


\section{Macrothink}

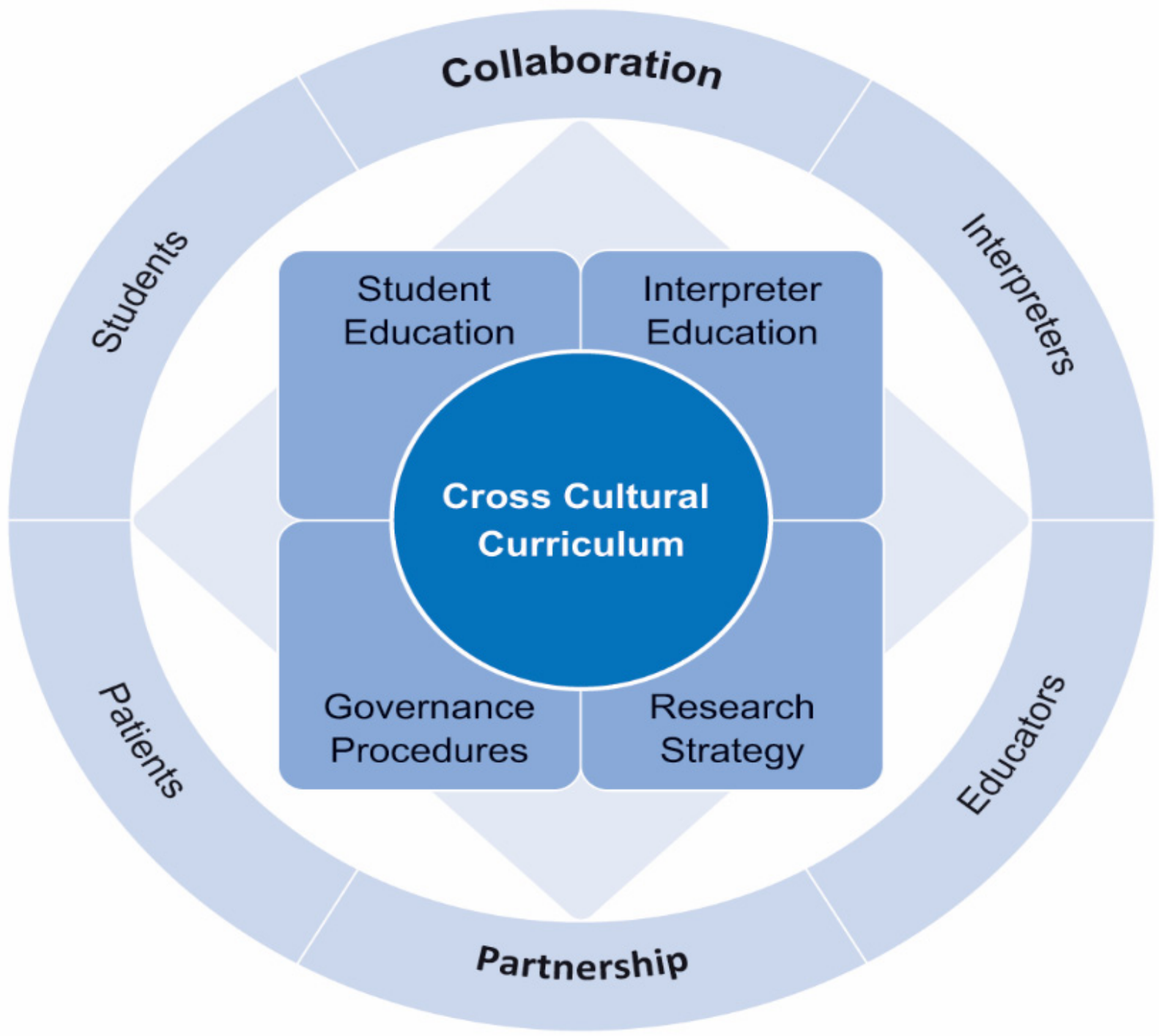

Figure 1. Language Interpreting Processes: A Guide for Educational Practice

\section{Conclusion}

This qualitative study illustrates the complexities of language interpreting and represents an important contribution to this ever-evolving knowledge base. It also provides a relatively unique insight into how an interpreted interaction (i.e., interpreting within a clinical medical examination), is viewed from the perspective of a variety of key stakeholders (i.e. students, interpreters, professors and examiners). While the findings illuminate divergent views and experiences relating to knowledge and communication, educational preparation and technological solutions, the pivotal role of the interpreter remains a constant and unifying theme. This paper also highlights the importance of ensuring that healthcare professionals are adequately prepared to practice effectively within language discordant situations. The framework 'Language Interpreting Processes: A Guide for Educational Practice' demonstrates how student education; interpreter education; governance procedures and research can be 


\section{Macrothink}

interwoven within a cross cultural curriculum to develop an effective strategy for educational practice.

\section{Practice Implications}

The educational preparation of healthcare professionals must incorporate strategies that are specifically designed to enable students to develop the requisite knowledge and skills to work effectively within language discordant clinical situations. Interpreting procedures/protocols should be based on a collaborative approach with students, interpreters and educators receiving appropriate educational preparation, predicated on a cross cultural approach to care. Robust governance procedures combined with a focused research strategy is also required. The aim is to create a learning environment that extends beyond challenges of linguistics and prepares healthcare professionals to deliver high quality healthcare to all patients particularly those from diverse social, racial, ethnic and cultural backgrounds.

\section{Acknowledgements}

The authors would like to thank the students, interpreters and educators who participated in the study and all those who supported its design and development.

\section{Ethics approval}

Institutional ethics approval was granted for the study by the University Human Research Ethics Committee. The authors confirm adherence to the standards of the Declaration of Helsinki and confirm that all participants provided written informed consent.

\section{Declaration of Interests}

This study was funded by the Royal College of Surgeons in Ireland (RCSI) - Bahrain (Grant No. BR00077). The authors report no conflicts of interest..

\section{References}

Albrecht, U.-V., Behrends, M., Matthies, H. K., \& von Jan, U. (2013). Usage of multilingual mobile translation applications in clinical settings. JMIR mHealth and uHealth, 1(1), e4. https://doi.org/10.2196/mhealth.2268

Beltran Avery, M. P. (2001). The role of the health care interpreter: An evolving dialogue. National Council on Interpreting in Health Care. Working Paper Series. Retrieved from Retrieved from http://www.ncihc.org/publications

Betancourt, J. R. (2003). Cross-cultural medical education: conceptual approaches and

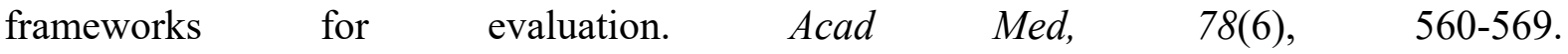
https://doi.org/10.1097/00001888-200306000-00004

Bowen, S. (2015). The impact of language barriers on patient safety and quality of care. Société Santé en français. Retrieved from https://journals.sagepub.com/doi/pdf/10.1177/2374373518769008 
Braun, V., \& Clarke, V. (2006). Using thematic analysis in psychology. Qualitative research in psychology, 3(2), 77-101. https://doi.org/10.1191/1478088706qp063oa

Brisset, C., Leanza, Y., \& Laforest, K. (2013). Working with interpreters in health care: a systematic review and meta-ethnography of qualitative studies. Patient Educ Couns, 91(2), 131-140. https://doi.org/10.1016/j.pec.2012.11.008

Cambridge, J., Singh, S. P., \& Johnson, M. (2012). The need for measurable standards in mental health interpreting: a neglected area. The Psychiatrist, 36(4), 121-124. https://doi.org/10.1192/pb.bp.110.031211

Chan, Y. F., Alagappan, K., Rella, J., Bentley, S., Soto-Greene, M., \& Martin, M. (2010). Interpreter services in emergency medicine. $J$ Emerg Med, 38(2), 133-139. https://doi.org/10.1016/j.jemermed.2007.09.045

Chang, D. T., Thyer, I., Hayne, D., \& Katz, D. (2014). Using mobile technology to overcome language barriers in medicine. The Annals of The Royal College of Surgeons of England, 96(6), e23-e25. https://doi.org/10.1308/003588414X13946184903685

Clarke, V., \& Braun, V. (2017). Thematic Analysis. The Journal of Positive Psychology, 12(3), 297-298. https://doi.org/10.1080/17439760.2016.1262613

Coetzee, D., Pereira, A. G., Scheurer, J. M., \& Olson, A. P. (2020). Medical Student Workshop Improves Student Confidence in Working With Trained Medical Interpreters. $J$ Med Educ Curric Dev, 7, 2382120520918862. https://doi.org/10.1177/2382120520918862

Coghlan, D. (2019). Doing action research in your own organization. London: SAGE Publications Limited.

Cox, A. (2015). Do you get the message? Defining the interpreter's role in medical interpreting in Belgium. MonTI. Monografías de Traducción e Interpretación, 161-184. https://doi.org/10.6035/MonTI.2015.ne2.6

Creswell, J. W., \& Creswell, J. D. (2017). Research Design: Qualitative, Quantitative, and Mixed Methods Approaches. SAGE Publications.

Diaz, J. E., Ekasumara, N., Menon, N. R., Homan, E., Rajarajan, P., Zamudio, A. R., . . . Soriano, R. P. (2016). Interpreter training for medical students: pilot implementation and assessment in a student-run clinic. BMC Med Educ, 16(1), 256. https://doi.org/10.1186/s12909-016-0760-8

Divi, C., Koss, R. G., Schmaltz, S. P., \& Loeb, J. M. (2007). Language proficiency and adverse events in US hospitals: a pilot study. Int J Qual Health Care, 19(2), 60-67. https://doi.org/10.1093/intqhe/mzl069

Flores, G. (2005). The impact of medical interpreter services on the quality of health care: a systematic review. Med Care Res Rev, 62(3), 255-299. https://doi.org/10.1177/1077558705275416 
Friedman-Rhodes, E., \& Hale, S. (2010). Teaching medical students to work with interpreters. The Journal of Specialised Translation, 14, 121-144. Retrieved from https://jostrans.org/issue14/art_friedman.pdf

Guba, E. G., \& Lincoln, Y. S. (1989). Fourth generation evaluation. California: Sage.

Ikram, U. Z., Essink-Bot, M.-L., \& Suurmond, J. (2015). How we developed an effective e-learning module for medical students on using professional interpreters. Medical teacher, 37(5), 422-427. https://doi.org/10.3109/0142159X.2014.939579

Juckett, G., \& Unger, K. (2014). Appropriate use of medical interpreters. American Family Physician, 90(7), 476-480.

Karliner, L. S., Jacobs, E. A., Chen, A. H., \& Mutha, S. (2007). Do professional interpreters improve clinical care for patients with limited English proficiency? A systematic review of the literature. Health services research, 42(2), 727-754. https://doi.org/10.1111/j.1475-6773.2006.00629.x

Kemmis, S., \& McTaggart, R. (1988). The action research planner. Victoria. Australia: Deakin University.

Kitzinger, J. (1995). Qualitative research. Introducing focus groups. Bmj, 311(7000), 299-302. https://doi.org/10.1136/bmj.311.7000.299

Krueger, R. A., \& Casey, M. A. (2015). Focus groups: A practical guide for applied research (5th ed.). Thousand Oaks CA: Sage Publications.

Krystallidou, D. (2014). Gaze and body orientation as an apparatus for patient inclusion into/exclusion from a patient-centred framework of communication. The Interpreter and Translator Trainer, 8(3), 399-417. https://doi.org/10.1080/1750399X.2014.972033

Krystallidou, D., Van De Walle, C., Deveugele, M., Dougali, E., Mertens, F., Truwant, A., . . . Pype, P. (2018). Training "doctor-minded" interpreters and "interpreter-minded" doctors: The benefits of collaborative practice in interpreter training. Interpreting, 20(1), 126-144. https://doi.org/10.1075/intp.00005.kry

Lambert, S. D., \& Loiselle, C. G. (2008). Combining individual interviews and focus groups to enhance data richness. $J$ Adv Nurs, 62(2), 228-237. https://doi.org/10.1111/j.1365-2648.2007.04559.x

Larrison, C. R., Velez-Ortiz, D., Hernandez, P. M., Piedra, L. M., \& Goldberg, A. (2010). Brokering language and culture: Can ad hoc interpreters fill the language service gap at community health centers? Social work in public health, 25(3-4), 387-407. https://doi.org/10.1080/19371910903241009

Lie, D. A., Bereknyei, S., \& Vega, C. P. (2010). Longitudinal development of medical students' communication skills in interpreted encounters. Educ Health (Abingdon), 23(3), 466. Retrieved from https://www.ncbi.nlm.nih.gov/pubmed/21290365 
McEvoy, M., Santos, M. T., Marzan, M., Green, E. H., \& Milan, F. B. (2009). Teaching medical students how to use interpreters: a three year experience. Medical education online, 14(1), 4507. https://doi.org/10.3402/meo.v14i.4507

Morgan, D. L., Krueger, R. A., \& Scannell, A. U. (1998). Planning focus groups. London: Sage. https://doi.org/10.4135/9781483328171

Ngo-Metzger, Q., Sorkin, D. H., Phillips, R. S., Greenfield, S., Massagli, M. P., Clarridge, B., \& Kaplan, S. H. (2007). Providing high-quality care for limited English proficient patients: the importance of language concordance and interpreter use. Journal of general internal medicine, 22(2), 324-330. https://doi.org/10.1007/s11606-007-0340-z

Omoruyi, E. A., Dunkle, J., Dendy, C., McHugh, E., \& Barratt, M. S. (2018). Cross Talk: Evaluation of a curriculum to teach medical students how to use telephone interpreter services. Academic pediatrics, 18(2), 214-219. https://doi.org/10.1016/j.acap.2017.11.010

Panayiotou, A., Gardner, A., Williams, S., Zucchi, E., Mascitti-Meuter, M., Goh, A. M., . . . Batchelor, F. (2019). Language Translation Apps in Health Care Settings: Expert Opinion. JMIR Mhealth Uhealth, 7(4), e11316. https://doi.org/10.2196/11316

Pasquandrea, S. (2011). Managing multiple actions through multimodality: Doctors' involvement in interpreter-mediated interactions. Language in Society, 40(4), 455-481. https://doi.org/10.1017/S0047404511000479

Rodriguez, F., Cohen, A., Betancourt, J. R., \& Green, A. R. (2011). Evaluation of medical student self-rated preparedness to care for limited English proficiency patients. BMC Med Educ, 11(1), 26. https://doi.org/10.1186/1472-6920-11-26

Rosenberg, E., Leanza, Y., \& Seller, R. (2007). Doctor-patient communication in primary care with an interpreter: physician perceptions of professional and family interpreters. Patient Educ Couns, 67(3), 286-292. https://doi.org/10.1016/j.pec.2007.03.011

Schwandt, T. A. (1994). Constructivist, interpretivist approaches to human inquiry. Handbook of qualitative research, 1, 118-137.

Seidelman, R. D., \& Bachner, Y. G. (2010). That I won't translate! Experiences of a family medical interpreter in a multicultural environment. Mount Sinai Journal of Medicine: A Journal of Translational and Personalized Medicine, 77(4), 389-393. https://doi.org/10.1002/msj.20189

Trunk Sirca, N., \& Shapiro, A. (2007). Action research and constructivism: two sides of the same coin? Or, one side? International Journal of Management in Education, 1(1-2), 100-107. https://doi.org/10.1504/IJMIE.2007.014380

van Rosse, F., de Bruijne, M., Suurmond, J., Essink-Bot, M. L., \& Wagner, C. (2016). Language barriers and patient safety risks in hospital care. A mixed methods study. Int J Nurs Stud, 54, 45-53. https://doi.org/10.1016/j.jinurstu.2015.03.012 


\section{Macrothink}

International Journal of Learning and Development

ISSN 2164-4063 2021, Vol. 11, No. 3

\section{Copyright Disclaimer}

Copyright for this article is retained by the author(s), with first publication rights granted to the journal.

This is an open-access article distributed under the terms and conditions of the Creative Commons Attribution license (http://creativecommons.org/licenses/by/4.0/). 